\title{
Antiepileptic Overdose
}

\author{
Shakuntala Murty
}

\begin{abstract}
Antiepileptics include various groups of drugs that have different mechanisms of actions and adverse effects. They are often also used to treat other disorders such as psychosis, chronic pain, and migraine. The most common drugs implicated in overdose include phenytoin, sodium valproate, carbamazepine, and phenobarbital. Common signs of toxicity of these drugs are central nervous system manifestations such as altered sensorium, lethargy, ataxia, and nystagmus. Some ingestions can paradoxically precipitate seizures and even status epilepticus. Sodium valproate can cause hyperammonemic encephalopathy and cerebral edema. Carbamazepine is implicated in cardiac arrhythmias and hyponatremia. Phenobarbital causes sedation, respiratory depression, and hypotension. In suspected overdose, apart from the routine laboratory tests, serum levels of the drug should be sent. Serial levels should be measured, as drug toxicity can be prolonged. Treatment of all these overdoses begins with stabilization of airway, breathing, and circulation, and endotracheal intubation being performed to protect the airway in patients with altered mental status. For decontamination, a single dose of activated charcoal should be given. Multidose of activated charcoal may be useful in phenytoin, carbamazepine, and phenobarbital overdose. Naloxone and carnitine are indicated in valproate overdose. Carbamazepine overdose can cause a widened QRS complex and arrhythmias, which can be treated with sodium bicarbonate. Forced alkaline diuresis is no longer advocated for phenobarbital poisoning. The Extracorporeal Treatments in Poisoning (EXTRIP) workgroup have formulated guidelines for extracorporeal removal of all these drugs. In most cases, hemodialysis is preferred. Other modalities include charcoal hemoperfusion (especially for carbamazepine) or continuous venovenous hemodialysis. Patients who ingest long-acting preparations should be monitored for longer periods. Keywords: Antiepileptics, Extracorporeal removal, Poisoning, Toxicology.

Indian Journal of Critical Care Medicine (2019): 10.5005/jp-journals-10071-23301
\end{abstract}

\section{INTRODUCTION}

The use of antiepileptics for seizure disorders began in 1912, with the use of phenobarbital. Over the last 100 years, several drugs have been introduced, with varying mechanisms of action against seizures. In the 1990s, newer drugs such as lamotrigine, topiramate, levetiracetam, and lacosamide with better safety profiles entered the market. Antiepileptics are also used to treat mood disorders, refractory pain syndromes, headaches, and social phobias. This chapter outlines the toxicity and management of overdose of four commonly prescribed antiepileptics - phenytoin, valproic acid, carbamazepine, and phenobarbital.

\section{Phenytoin and Fosphenytoin}

Phenytoin is one of the oldest antiepileptics still commonly prescribed as a first-line drug. Phenytoin toxicity causes neurologic symptoms and cardiac effects-intravenous (IV) administration can cause the purple glove syndrome (PGS). Fosphenytoin, a water-soluble phosphate ester prodrug of phenytoin, was introduced in 1997. It can be given intramuscularly and has a lower risk of tissue injury when given IV.

\section{Pharmacology and Pharmacokinetics}

Phenytoin blocks voltage-gated sodium channels found on both neuronal and cardiac tissues. The membrane threshold for depolarization is increased, thus lowering the susceptibility of neuronal tissues to epileptogenic stimuli. Excessive inhibition impairs cerebral function leading to incoordination and altered mental status. At toxic concentrations, both high-frequency and spontaneous sodium channels including those in cardiac tissues responsible for action potential initiation are inhibited, leading to reduced action potential duration and prolonged refractory periods. ${ }^{1}$ These changes predispose to arrhythmias, predominantly with parenteral administration and very rarely with oral use. ${ }^{2}$
Department of Emergency Medicine, St. John's Medical College and Hospital, Bengaluru, Karnataka, India

Corresponding Author: Shakuntala Murty, Department of Emergency Medicine, St. John's Medical College and Hospital, Bengaluru, Karnataka, India, Phone: +91 9900196307, e-mail: drshaku63@yahoo.co.in

How to cite this article: Murty S. Antiepileptic Overdose. Indian J Crit Care Med 2019;23(Suppl 4):S290-S295.

Source of support: Nil

Conflict of interest: None

With IV use, the main toxicity is believed to be from its vehicle, propylene glycol which is a cardiac depressant. Rapid infusions can lead to bradycardia, hypotension, and asystole. ${ }^{1}$ Hence, IV phenytoin should not be administered at a rate faster than $50 \mathrm{mg} /$ minute.

Phenytoin is bound significantly to plasma albumin and can be displaced from it by several drugs, leading to toxicity. At higher serum concentrations, free phenytoin levels increase markedly. It is hydroxylated by the cytochrome $\mathrm{P} 450$ system, which gets saturated in overdose, leading to a prolonged half-life of 24-230 hours.

Fosphenytoin is converted to phenytoin by serum and tissue alkaline phosphatases. It does not contain propylene glycol, hence rapid IV infusion may be safer, though occasional cases of cardiac toxicity have been reported. ${ }^{3}$

\section{Clinical Features of Acute Toxicity Neurotoxicity}

Acute toxicity affects the cerebellar and vestibular systems causing (Table 1):

- Nystagmus, ataxia, impaired coordination initially

- Slurred speech, pyramidal, and extrapyramidal manifestations later

- Rarely seizures

o The Author(s). 2019 Open Access This article is distributed under the terms of the Creative Commons Attribution 4.0 International License (https://creativecommons. org/licenses/by-nc/4.0/), which permits unrestricted use, distribution, and non-commercial reproduction in any medium, provided you give appropriate credit to the original author(s) and the source, provide a link to the Creative Commons license, and indicate if changes were made. The Creative Commons Public Domain Dedication waiver (http://creativecommons.org/publicdomain/zero/1.0/) applies to the data made available in this article, unless otherwise stated. 
Table 1: Correlation of serum phenytoin level and clinical features ${ }^{5}$

\begin{tabular}{ll}
\hline Serum levels & Toxic effect \\
\hline$<10 \mathrm{mg} / \mathrm{L}$ & Rare side effects \\
$10-20 \mathrm{mg} / \mathrm{L}$ & $\begin{array}{l}\text { Occasional mild horizontal nystagmus on } \\
\text { lateral gaze }\end{array}$ \\
$20-30 \mathrm{mg} / \mathrm{L}$ & $\begin{array}{l}\text { Nystagmus } \\
\text { Ataxia, slurred speech, tremor, nausea, and } \\
\text { vomiting }\end{array}$ \\
$40-50 \mathrm{mg} / \mathrm{L}$ & Lethargy, confusion \\
$>50 \mathrm{mg} / \mathrm{L}$ & Coma, seizures \\
\hline
\end{tabular}

Children and infants may present with atypical features. Decreased appetite, poor feeding, chorea, and opisthotonic posturing have been reported in infants. ${ }^{4}$ Compared to adults, children may manifest toxicity at lower serum concentrations, and presentation may be subtle with limited examination findings.

\section{Cardiac Toxicity}

The common cardio toxicities are dysrhythmias, sinoatrial (SA) and atrioventricular (AV) nodal block, bradycardia, and hypotension with rapid IV administration.

\section{Purple Glove Syndrome}

It typically occurs within 24 hours of IV infusion and presents with edema, blisters, pain, and discoloration of the extremity. ${ }^{6}$ Sensation and peripheral pulses may be diminished and skin necrosis may develop. The mechanism may be irritation from propylene glycol, vasoconstriction, vasculitis or microthrombus formation, or phenytoin leakage into soft tissue. The use of large bore cannulas or central lines for administration may decrease the incidence of PGS.

\section{LABORATORY TESTS}

\section{General Investigations}

General investigation such as electrocardiograph (ECG), blood glucose, serum electrolytes, liver function tests, and serum albumin are made. Patients with hypoalbuminemia may have significant toxicity with a therapeutic or mildly elevated phenytoin level, as their free phenytoin levels are higher. Hepatic dysfunction increases the risk of phenytoin toxicity.

\section{Specific Testing}

Total serum phenytoin concentrations should be measured and repeated if patients with acute overdose deteriorate rapidly. Serial phenytoin concentrations should be obtained roughly every 2 hours until the level begins to fall, as it can increase during the first several hours, especially if gastrointestinal decontamination is inadequate.

\section{MANAGEMENT}

\section{General}

Airway and breathing should be stabilized. Comatose patients may require endotracheal intubation. Lidocaine should be avoided during rapid sequence intubation, as it has the same antiarrhythmic properties as phenytoin.

Bradyarrhythmias usually resolve after stopping the infusion but may require drug treatment with atropine, epinephrine, or dopamine and rarely transcutaneous or transvenous pacing. Hypotension responds to boluses of isotonic saline. Prolonged QT interval during fosphenytoin infusion may be due to hyperphosphatemia and hypocalcemia, which should be rapidly corrected.

\section{Decontamination}

A single dose of activated charcoal can be given in ingestions within several hours, provided the patient is alert and able to protect the airway. Patients presenting with central nervous system (CNS) depression are at risk of charcoal aspiration. Multidose of activated charcoal has been used in patients whose phenytoin concentrations remained persistently elevated due to impaired metabolism. It may help to remove unbound phenytoin undergoing enterohepatic circulation even in IV overdose or in case of chronic phenytoin toxicity. ${ }^{7}$ Gastric lavage and whole-bowel irrigation are not recommended.

\section{Extracorporeal Removal}

In spite of high protein binding, phenytoin is moderately dialyzable. Intermittent hemodialysis or hemoperfusion has been proposed by the EXTRIP workgroup in cases of severe poisoning with prolonged coma or prolonged incapacitating ataxia. ${ }^{8}$

\section{Seizures}

Benzodiazepines are the first-line medications, followed by phenobarbital or levetiracetam for persistent or recurrent seizures.

\section{Purple Glove Syndrome}

Various suggested treatments are topical nitroglycerin, brachial plexus nerve block, elevation, application of heat and massage of the limb. In case of digital or skin necrosis, vascular or plastic surgery consultation should be obtained. The affected limb should be elevated above the heart and adequate analgesia provided. Observation should be continued for at least 24 hours.

Once the medical symptoms resolve, psychiatric consultation is needed for all cases of intentional ingestion.

\section{Valproic ACID}

Valproic acid (2-propylpentanoic acid; VPA) is a branched-chain carboxylic acid used to treat partial and generalized seizures and acute mania and as prophylaxis for bipolar disorder and migraine headaches. It has multiple mechanisms of action including blocking of voltage-dependent sodium channels, increasing brain gammaaminobutyric acid (GABA) concentrations by a presynaptic effect on $G A B A(B)$ receptors, inhibiting nerve terminal GABA transaminase (GABA-T), and also increasing the synthesis of GABA by activating glutamic acid decarboxylase. 2-Propylpentanoic acid acts weakly against T-type calcium currents. Stimulation of the $N$-methyl-Daspartate (NMDA) receptor by glutamate activates a ligand-gated ion channel that permits the entry of $\mathrm{Na}^{+}$and $\mathrm{Ca}^{2+}$ into the neuronal cells. Suppression of the glutamate-NMDA interaction protects against seizures. 2-Propylpentanoic acid is a possible competitive glutamate antagonist at the NMDA receptor.

\section{Pharmacology and Pharmacokinetics}

Peak plasma concentrations occur 1-4 hours after ingestion of nonenteric-coated tablets and 4-5 hours after therapeutic doses of enteric-coated tablets but may be markedly delayed following overdose. ${ }^{9}$ A multicenter study of VPA ingestions revealed a meantime to peak plasma concentration of $7.4 \pm 3.9$ hours; $14 \%$ of patients had peak concentrations delayed greater than 10 hours. ${ }^{10}$ In all, $80-90 \%$ of VPA binds to plasma proteins and has a small 
volume of distribution. It is metabolized extensively by the liver via glucuronic acid conjugation and beta and omega oxidation to produce multiple metabolites, some of which are biologically active. Omega oxidation generates toxic metabolites of VPA that cause the hepatic, metabolic, and neurologic adverse effects. Less than $3 \%$ of VPA is excreted unchanged in the urine.

\section{Clinical Features of Acute Toxicity}

Most commonly VPA poisoning presents with CNS dysfunction such as drowsiness, coma, or severe cerebral edema. ${ }^{11}$ Other clinical findings include respiratory depression, hypotension, tachycardia, hyperthermia, vomiting, diarrhea, tremors, and myoclonus. Massive overdoses can lead to bone marrow suppression. Pancreatitis, hepatotoxicity, and acute kidney injury are rarely seen.

\section{Cerebral Edema}

Following acute overdose, cerebral edema is seen 12 hours to 4 days after ingestion, most commonly with ingestion of greater than 200 $\mathrm{mg} / \mathrm{kg}$ or serum concentrations greater than $180 \mathrm{mg} / \mathrm{L}$ and may result in herniation, ischemia, and focal neurologic deficits. It is likely to be due to the accumulation of 2-EN-VPA metabolite in brain and plasma. This has a prolonged elimination half-life, hence the prolonged coma seen in some patients in spite of the normal VPA levels.

\section{Valproate-induced Hyperammonemic Encephalopathy}

This is characterized by impaired consciousness with confusion or lethargy, focal or bilateral neurologic signs, and increased seizure frequency. It is not always accompanied by elevated VPA concentrations or abnormal liver function tests. ${ }^{12}$ It may be due to elevated ammonia concentrations ( $>80 \mu \mathrm{g} / \mathrm{dL}$ or $47 \mu \mathrm{mol} / \mathrm{L}$ ) as well as elevated concentrations of neurotoxic VPA metabolites. ${ }^{13}$ Hyperammonemia may be due to inhibition of mitochondrial carbamoyl phosphate synthetase, an enzyme necessary for ammonia elimination, by propionic acid which is a VPA metabolite, or interaction of VPA with carnitine.

\section{Hepatotoxicity}

This may be dose related and reversible, manifesting as minor elevations in aminotransferases. Discontinuation of the drug usually results in complete resolution of these abnormalities, though idiosyncratic fulminant hepatic failure and death (with histopathologic changes similar to those of Reye syndrome) have also occurred. The incidence of hepatic failure is higher when valproic acid is administered with another medication (most often antiepileptics or benzodiazepines) as opposed to monotherapy.

\section{Metabolic Complications}

Metabolic complications are hypernatremia, hypocalcemia, aniongap metabolic acidosis, and hyperammonemia.

\section{LABORATORY TESTS}

\section{General Testing}

General testing done are ECG, blood glucose, platelet count, serum electrolytes, liver function tests, and plasma ammonia.

\section{Valproic Acid Levels}

Therapeutic serum concentrations of VPA range from 50 to $100 \mathrm{mg} / \mathrm{L}$ (350 to $700 \mu \mathrm{mol} / \mathrm{L}$ ). Serial concentrations should be done every 2 to 4 hours until a steady decline in level is noted.
Serum concentrations greater than $180 \mathrm{mg} / \mathrm{L}(1,260 \mu \mathrm{mol} / \mathrm{L})$ are usually associated with some degree of CNS depression.

\section{Computed Tomography of Head}

Patients with VPA toxicity and focal neurologic deficits, elevated plasma ammonia, or altered mental status for more than 12 hours after an acute overdose should go for a Computed Tomography (CT) of head to look for cerebral edema.

\section{Management}

\section{General}

Patients with altered sensorium may need endotracheal intubation for airway protection. Seizures can be treated with benzodiazepines. Most patients do well with good supportive care.

\section{Decontamination}

Single-dose activated charcoal $1 \mathrm{~g} / \mathrm{kg}$ should be given to patients presenting within 2 hours of acute ingestion, except those who cannot protect the airway. Multiple-dose activated charcoal is not recommended. Forced diuresis is ineffective as very little free VPA is excreted by the kidney.

\section{Naloxone}

Naloxone has been reported to reverse CNS depression; hence, it can be tried in patients with acute VPA poisoning and CNS depression. The risks associated with the treatment are low. It should be withheld in known or suspected opioid addiction. Initial dose is $0.04 \mathrm{mg} \mathrm{IV}$, titrated upward every few minutes until the patient responds or a maximum single dose of $2 \mathrm{mg} I \mathrm{~V}$ is given. Additional doses can be given in $2 \mathrm{mg}$ increments up to a total dose of $10 \mathrm{mg}$.

\section{Carnitine Supplementation}

2-Propylpentanoicacid increases carnitine excretion by the formation of valproylcarnitine which is renally excreted. Valproylcarnitine inhibits the adenosine triphosphate (ATP)-dependent carnitine transporter. 2-Propylpentanoic acid metabolites also trap mitochondrial CoA decreasing ATP production, which in turn negatively affects the carnitine transporter. Carnitine treatment may help hyperammonemia and hepatotoxicity. Indications include:

- Coma

- Severe hepatotoxicity

- 2-Propylpentanoic acid serum concentration $>450 \mu \mathrm{g} / \mathrm{mL}$ $(>3,120 \mu \mathrm{mol} / \mathrm{L})$

- Hyperammonemic encephalopathy

- Asymptomatic hyperammonemia with significant VPA toxicity

The L-carnitine dose is $100 \mathrm{mg} / \mathrm{kg}$ IV over 30 minutes (maximum dose $6 \mathrm{~g}$ ), followed by $50 \mathrm{mg} / \mathrm{kg} \mathrm{IV}$ (maximum dose $3 \mathrm{~g}$ ) given every eight hours. ${ }^{14,15}$

Treatment should be continued until the clinical signs of severe poisoning resolve. For patients with an acute overdose of VPA, but no clinical or laboratory signs of toxicity, oral carnitine can be administered prophylactically at a dose of $100 \mathrm{mg} / \mathrm{kg}$ per day (up to $3 \mathrm{~g}$ total) divided every 6 hours.

\section{Hemodialysis and Hemoperfusion}

2-Propylpentanoic acid has a low molecular weight and low volume of distribution; hence, extracorporeal removal may be effective. ${ }^{16}$ At higher serum levels, protein-binding sites become saturated 
and free drug concentrations increase, which can be cleared by dialysis. Hemodialysis can also reverse VPA-associated metabolic abnormalities, including elevated ammonia.

The EXTRIP workgroup provided guidelines based upon a systematic review of 79 articles involving extracorporeal removal. Intermittent hemodialysis is preferred, but if unavailable, intermittent hemoperfusion or continuous renal replacement therapy are acceptable.

\section{Definite Indications}

- 2-Propylpentanoic acid concentration $>1,300 \mathrm{mg} / \mathrm{L}(>9,000$ $\mu \mathrm{mol} / \mathrm{L})$

- Cerebral edema

- Shock

\section{Possibly Effective}

- 2-Propylpentanoic acid concentration $>900 \mathrm{mg} / \mathrm{L}(>6,250$ $\mu \mathrm{mol} / \mathrm{L})$

- Coma or respiratory depression requiring mechanical ventilation

- $\mathrm{pH}<7.10$

- Acute hyperammonemic encephalopathy

Treatment should be continued until clinical improvement such as improved mental status, normal hemodynamics, and improving electrolyte and acid-base abnormalities or decreasing VPA levels to between $50 \mathrm{mg} / \mathrm{L}$ and $100 \mathrm{mg} / \mathrm{L}$ (350 and $700 \mu \mathrm{mol} / \mathrm{L}$ ).

\section{Disposition}

Patients with severe signs and symptoms of poisoning, large ingestions, or very high serum level will need intensive care unit (ICU) admission. Asymptomatic patients who have taken immediate-release preparations should be observed closely for 6 hours and the VPA level is obtained. If the level is low, further deterioration is unlikely. Patients who ingest delayedrelease or extended-release preparations of VPA should be observed for at least 12 hours. Serial serum VPA concentrations should be obtained and rising levels require admission even if asymptomatic.

\section{Carbamazepine}

Carbamazepine is a first-line antiseizure agent, which is structurally related to the cyclic antidepressants.

\section{Pharmacology and Pharmacokinetics}

Carbamazepine has slow and unpredictable absorption after oral administration, with peak concentrations achieved 12-24 hours after ingestion, especially with sustained release preparations. It is 75-90\% protein bound and has weak anticholinergic properties. It binds to sodium channels, hence inhibiting neuronal depolarization and decreasing glutamate release. Sodium channel blockade in cardiac tissues may cause QRS interval prolongation, predisposing to ventricular arrhythmias and hypotension. ${ }^{17}$ It inhibits presynaptic reuptake of adenosine, resulting in modulation and inhibition of glutamate neurotransmission. But in overdose, adenosine receptors are antagonized, leading to a proconvulsant effect.

Metabolism is primarily in the liver through cytochrome P450 (CYP) 3A4. It can induce multiple cytochrome P450 isoenzymes, hence taking part in several drug-drug interactions. Erythromycin, fluoxetine, and cimetidine increase carbamazepine levels, whereas phenytoin and phenobarbital decrease them.

\section{Clinical Features of Acute Toxicity}

Carbamazepine poisoning may present with neurological, cardiovascular, or anticholinergic symptoms.

\section{Neurotoxicity}

Nystagmus, dysarthria, ataxia, lethargy, and fluctuating levels of consciousness and coma may occur. Agitation, choreoathetosis, and dyskinesia have been described. Seizures may be precipitated and some patients present with an increase in seizure frequency or even status epilepticus. ${ }^{18}$ Myoclonus, hypertonia, or hypotonia may occur. Ocular examination may reveal nystagmus, mydriasis, or rarely ophthalmoplegia.

\section{Cardiovascular Toxicity}

Sinus tachycardia (seen in 35\% of overdoses), hypotension due to myocardial depression and cardiac conduction abnormalities may occur. Bradycardia, atrioventricular block, premature ventricular contractions, ventricular tachycardia, and junctional escape rhythms have been described. Prolonged QRS complex and QT interval are often seen. Abnormalities in ECG are less common in children.

\section{Anticholinergic Effects}

Anticholinergic effects are hyperthermia, flushed skin, dry mucous membranes, hypoactive, absent bowel sounds, or urinary retention.

\section{Hyponatremia}

This occurs due to increased antidiuretic hormone secretion [syndrome of inappropriate antidiuretic hormone (SIADH)] or increased sensitivity of peripheral osmoreceptors to $\mathrm{ADH} .{ }^{19}$

\section{LABORATORY TESTING \\ General Testing}

General testing includes fingerstick glucose, ECG to look for QRS prolongation and arrhythmias, creatine phosphokinase as rhabdomyolysis has been described, and serum electrolytes.

\section{Serum Carbamazepine Levels}

Serial levels should be done every 4-6 hours until a decreasing trend is achieved and patient is improving clinically. Therapeutic levels are $4-12 \mu \mathrm{g} / \mathrm{mL}$ (17-51 $\mu \mathrm{mol} / \mathrm{L})$. Levels above $40 \mu \mathrm{g} / \mathrm{mL}$ correlate with severe toxicity. Seizures occur only in patients with known epilepsy and serum levels $>25 \mu \mathrm{g} / \mathrm{mL}$.

\section{Management}

\section{Airway, Breathing, and Circulation}

Patients with altered mental status may need to be intubated. Hypotension should be initially treated with isotonic crystalloid, while monitoring for fluid overload in view of possible myocardial dysfunction. Persistent hypotension can be managed with norepinephrine.

\section{Decontamination}

A single dose of activated charcoal $1 \mathrm{~g} / \mathrm{kg}$, maximum dose $50 \mathrm{~g}$, can be given to patients with a normal mental status who present within 1 to 2 hours of an acute overdose and are able to protect 
their airway but should be withheld in patients with CNS depression. The role of multidose-activated charcoal is controversial, with some literature showing benefit-hence it may be considered but is not routinely recommended. ${ }^{20}$

\section{Seizures}

These should be treated with benzodiazepines. Intubated patients can be given a continuous propofol infusion. Phenytoin has no role.

\section{QRS prolongation}

Sodium channel blockade may cause QRS prolongation, which predisposes to ventricular arrhythmias. This can be treated with sodium bicarbonate bolus of 100-150 mEq for QRS intervals of more than 110 milliseconds, especially in patients with hypotension. Repeat boluses may be required.

\section{Extracorporeal Elimination}

Patients with refractory seizures, hemodynamic instability, or life-threatening dysrhythmias are candidates for hemodialysis. High-flux hemodialysis is preferred. Among other methods such as continuous venovenous hemodialysis with albumin dialysate, charcoal hemoperfusion, and plasma exchange, charcoal hemoperfusion may be a useful adjunct. ${ }^{21,22}$

\section{Phenobarbital}

Barbiturates belong to the sedative-hypnotic group of drugs. Phenobarbital is one of the oldest antiseizure drugs still in use and is effective for generalized and focal seizures. Among all barbiturates, phenobarbital is most commonly associated with overdose.

\section{Pharmacology and Pharmacokinetics}

Phenobarbital acts by enhancing the function of GABA-mediated chloride channels via agonist at the $G_{A B A}{ }^{A}$ receptor. It is metabolized primarily in the liver by the cytochrome system. $25 \%$ is excreted unchanged by the kidney. It is slowly absorbed and distributed and hence has a long duration of action. It induces hepatic enzymes, thus increasing the metabolism of other medications. The elimination of phenobarbital can be enhanced 5-10-fold through urinary alkalinization to a $\mathrm{pH}$ of 7.5-8.0, a property that is useful in the setting of overdose.

\section{Clinical Features of Acute Toxicity 23 Neurological}

Neurological effects are decreased level of consciousness progressing to coma, slurred speech, faulty judgment, poor coordination, vertigo, muscle weakness, dilated or contracted pupils.

\section{Cardiovascular}

Cardiovascular effects are bradycardia and hypotension.

\section{Respiratory}

Respiratory effects are respiratory depression and pulmonary edema.

\section{General}

General symptoms are nausea, hypothermia, thirst, oliguria, and bullous fixed drug eruptions.

Coingestion of ethanol, benzodiazepines, and opiates can lead to additive effects.

\section{LABORATORY TESTING}

\section{General}

General lab testing includes blood glucose, serum electrolytes, arterial blood gas, and renal and liver function tests.

\section{Serum Phenobarbital Levels}

The therapeutic range for anticonvulsant activity of phenobarbital is $10-25 \mathrm{mg} / \mathrm{L}$. Serum concentrations of $>50 \mathrm{mg} / \mathrm{L}$ may induce coma, and concentrations $>80 \mathrm{mg} / \mathrm{L}$ may be fatal.

\section{Management}

\section{Airway, Breathing, and Circulation}

Patients who are sedated or have respiratory depression will need to be intubated and mechanically ventilated. Hypotension is treated with IV crystalloid boluses, followed by vasopressors for persistent hypotension.

\section{Decontamination}

Activated charcoal can be given for patients without airway compromise. Multidose-activated charcoal has been reported to increase phenobarbital elimination by $50-80 \%$, though a controlled study did not show any statistical benefit compared to single dose. Multidose-activated charcoal (MDAC) 15-20 g orally every 6 hours should be administered only after airway protection and hemodynamic stabilization. ${ }^{24-27}$

\section{Forced Alkaline Diuresis (Urine Alkalinization)}

This treatment was earlier used for phenobarbital poisoning but now cannot be recommended as the first-line treatment, as comparative studies have found MDAC to be superior. ${ }^{28}$

\section{Extracorporeal Toxin Removal}

The EXTRIP workgroup made the following recommendations for extracorporeal treatment of barbiturate poisoning following a systematic review. ${ }^{29}$

- The use of extracorporeal toxin removal (ECTR) should be restricted to cases of severe long-acting barbiturate poisoning.

- Indications for ECTR in this setting are prolonged coma, respiratory depression necessitating mechanical ventilation, shock in spite of fluid resuscitation, persistent toxicity, or increasing or persistently elevated serum barbiturate concentrations despite treatment with MDAC.

- Intermittent hemodialysis is the preferred mode of ECTR, and MDAC treatment should be continued during ECTR. Hemoperfusion or continuous renal replacement therapy (CRRT) is the acceptable alternative modality in adults if hemodialysis (HD) is not available

- Cessation of ECTR is indicated when clinical improvement is apparent. Survival with supportive therapy is excellent, mortality rates associated with barbiturate toxicity being less than $2 \%$. Patients should be managed in the ICU with close monitoring.

\section{References}

1. Mixter 3rd CG, Moran JM, Austen WG. Cardiac and peripheral vascular effects of diphenylhydantoin sodium. Am J Cardiol 1966;17(3): 332-338. DOI: 10.1016/0002-9149(66)90216-5. 
2. Adams BD, Buckley NH, Kim JY, Tipps LB. Fosphenytoin may cause hemodynamically unstable bradydysrhythmias. J Emerg Med 2006;30(1):75-79. DOI: 10.1016/j.jemermed.2005.01.034.

3. Browne TR, Kugler AR, Eldon MA. Pharmacology and pharmacokinetics of fosphenytoin. Neurology 1996;46(6 Suppl 1):S3-S7. DOI: 10.1212/ WNL.46.6_Suppl_1.3S.

4. Lowry JA, Vandover JC, DeGree J, Scalzo AJ. Unusual presentation of iatrogenic phenytoin toxicity in a newborn. J Med Toxicol 2005;1(1):26-29. DOI: 10.1007/BF03160902.

5. Iorga A, Horowitz BZ. StatPearls. Phenytoin Toxicity. Treasure Island (FL): StatPearls Publishing; 2019.

6. O'Brien TJ, Cascino GD, So EL, Hanna DR. Incidence and clinical consequence of the purple glove syndrome in patients receiving intravenous phenytoin. Neurology 1998;51(4):1034-1039. DOI: 10.1212/WNL.51.4.1034.

7. SkinnerCG, Chang AS, Matthews AS, ReedySJ, Morgan BW. Randomized controlled study on the use of multiple-dose activated charcoal in patients with supratherapeutic phenytoin levels. Clin Toxicol (Phila) 2012;50(8):764-769. DOI: 10.3109/15563650.2012.716159.

8. Anseeuw K, Mowry JB, Burdmann EA, Ghannoum M, Hoffman RS, Gosselin S, et al. Extracorporeal treatment in phenytoin poisoning: systematic review and recommendations from the EXTRIP (extracorporeal treatments in poisoning) workgroup. Am J Kidney Dis 2016;67(2):187-197. DOI: 10.1053/j.ajkd.2015.08.031.

9. Ingels M, Beauchamp J, Clark RF, Williams SR. Delayed valproic acid toxicity: a retrospective case series. Ann Emerg Med 2002;39(6): 616-621. DOI: 10.1067/mem.2002.124443.

10. Spiller HA, Krenzelok EP, Klein-Schwartz W, Winter ML, Weber $J A$, Sollee DR, et al. Multicenter case series of valproic acid ingestion: serum concentrations and toxicity. J Toxicol Clin Toxicol 2000;38(7):755-760. DOI: 10.1081/CLT-100102388.

11. Sztajnkrycer MD. Valproic acid toxicity: overview and management.J Toxicol Clin Toxicol 2002;40(6):789-801. DOI: 10.1081/CLT-120014645.

12. Dealberto MJ.Valproate-induced hyperammonaemic encephalopathy: review of 14 cases in the psychiatric setting. Int Clin Psychopharmacol 2007;22(6):330-337. DOI: 10.1097/YIC.0b013e3281c61b28.

13. Eyer F, Felgenhauer N, Gempel K, Steimer W, Gerbitz KD, Zilker T. Acute valproate poisoning: pharmacokinetics, alteration in fatty acid metabolism, and changes during therapy. J Clin Psychopharmacol 2005;25(4):376-380. DOI: 10.1097/01.jcp.0000168485.76397.5c.

14. Howland MA. L-Carnitine. In: Goldfrank's Toxicological Emergencies, 9th ed., New York: McGraw Hill Medical; 2011. p. 711

15. Perrott J, Murphy NG, Zed PJ. L-Carnitine for acute valproic acid overdose: a systematic review of published cases. Ann Pharmacother 2010;44(7-8):1287-1293. DOI: 10.1345/aph.1P135.

16. Ghannoum M, Laliberté M, Nolin TD, MacTier R, Lavergne $V$, Hoffman RS, et al. Extracorporeal treatment for valproic acid poisoning: systematic review and recommendations from the EXTRIP workgroup. Clin Toxicol (Phila) 2015;53(5):454-465. DOI: 10.3109/15563650.2015.1035441.

17. Durelli L, Massazza U, Cavallo R. Carbamazepine toxicity and poisoning. Incidence, clinical features and management. Med Toxicol Adverse Drug Exp 1989;4(2):95-107. DOI: 10.1007/ BF03259906.

18. Doyon S. Antiepileptics. In: Goldfrank's Toxicological Emergencies, 9th ed., New York: McGraw Hill Medical; 2011. pp. 646

19. Kuz GM, Manssourian A. Carbamazepine-induced hyponatremia: assessment of risk factors. Ann Pharmacother 2005;39(11):1943-1946. DOI: 10.1345/aph.1G209.

20. Brahmi N, Kouraichi N, Thabet H, Amamou M. Influence of activated charcoal on the pharmacokinetics and the clinical features of carbamazepine poisoning. Am J Emerg Med 2006;24(4):440-443. DOI: 10.1016/j.ajem.2005.12.025.

21. Pilapil M, Petersen J. Efficacy of hemodialysis and charcoal hemoperfusion in carbamazepine overdose. ClinToxicol 2008;46(4):342-343. DOI: 10.1080/15563650701264300.

22. Ghannoum M, Yates C, Galvao TF, Sowinski KM, Vo TH, Coogan A, et al. Extracorporeal treatment for carbamazepine poisoning: systematic review and recommendations from the EXTRIP workgroup. Clin Toxicol (Phila) 2014;52(10):993-1004. DOI: 10.3109/15563650.2014.973572.

23. Suddock JT, Cain MD. StatPearls. Barbiturate toxicity 2019.

24. Berg MJ, Berlinger WG, Goldberg MJ, Spector R, Johnson GF. Acceleration of the body clearance of phenobarbital by oral activated charcoal. N Engl J Med 1982;307(11):642-644. DOI: 10.1056/ NEJM198209093071102.

25. Berg MJ, Rose JQ, Wurster DE, Rahman S, Fincham RW, Schottelius DD. Effect of charcoal and sorbitol-charcoal suspension on the elimination of intravenous phenobarbital. Ther Drug Monit 1987;9(1):41-47. DOI: 10.1097/00007691-198703000-00008.

26. Boldy DA, Vale JA, Prescott LF. Treatment of phenobarbitone poisoning with repeated oral administration of activated charcoal. Q J Med 1986;61(235):997-1002.

27. Pond SM, Olson KR, Osterloh JD, Tong TG. Randomized study of the treatment of phenobarbital overdose with repeated doses of activated charcoal. JAMA 1984;251(23):3104-3108. DOI: 10.1001/ jama.1984.03340470030021.

28. Proudfoot AT, Krenzelok EP, Vale JA. Position paper on urine alkalinization. J Toxicol Clin Toxicol 2004;42(1):1-26. DOI: 10.1081/ CLT-120028740.

29. Mactier R, Laliberté M, Mardini J, Ghannoum M, Lavergne V, Gosselin S, Hoffman RS, et al. Extracorporeal treatment for barbiturate poisoning: recommendations from the EXTRIP workgroup. Am J Kidney Dis 2014;64(3):347-358. DOI: 10.1053/j.ajkd.2014.04.031. 